\title{
FT-Raman and FT-Infrared investigations of archaeological artefacts from Foeni Neolithic site (Banat, Romania)
}

\author{
Simona CÎNTĂ PÎNZARU1, Dana POP²* \& Loredana NEMETH $^{3}$ \\ ${ }^{1}$ Molecular Spectroscopy Department, „Babeş-Bolyai” University, Kogălniceanu 1, 400084 Cluj Napoca, Romania \\ ${ }^{2}$ Mineralogical Museum, „Babeş-Bolyai” University, Kogălniceanu 1, 400084 Cluj Napoca, Romania \\ ${ }^{3}$ Faculty of History and Philosophy, „Babeş-Bolyai” University, Kogălniceanu 1, 400084 Cluj Napoca, Romania
}

Received March 2008; accepted July 2008

Available online 25 August 2008

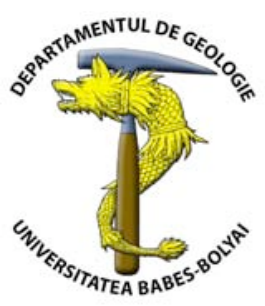

\begin{abstract}
An impressive collection of chert artefacts from the Foeni Neolithic archaeological site (Timiş County, Banat region, Romania) is hosted by the Banat Museum in Timişoara. A representative set of seven specimens was non-destructively investigated using FT-Raman and ATR-FT-IR spectroscopy. The research was carried out for checking if these readily available, non-destructive, fast, and cheap methods, which do not require preliminary sample preparation could provide significant information for characterizing the mineral composition of chert artefacts. Based on vibrational data, it was confirmed that the raw material was represented by microcrystalline quartz and moganite, with local concentrations of accessory minerals (calcite, dolomite, and clay minerals). In spite of their wide macroscopic heterogeneity (colour, transparency), based on single point FT-Raman measurements the chert artefacts could not be assigned to distinctive groups of raw silica materials, in order to provide specific arguments for provenance studies. However, the presence of specific accessory minerals (dolomite, illite) pointed to distinctive genetic conditions in the case of one lithic material. Sets of measurements (mapping) are required for statistically characterizing each artefact specimen. IR data were less significant, due to the rough surface texture of the specimens in contact with the ZnSe crystal of the ATR-FT-IR module. However, illite was identified based solely on its contribution to the IR spectrum. This pioneering study on chert artefacts from Romania based on optical spectroscopic methods shows that there are good premises for a systematic investigation of highly valuable museum collections, in particular in terms of chert geology.
\end{abstract}

Key words: Raman spectroscopy, IR spectroscopy, archaeology, Neolithic, chert/flint, microcrystalline silica.

\section{INTRODUCTION}

The identification of the raw materials used for manufacturing archaeological, historical and art objects is of great importance for giving insights into the technique or material applied in a certain period or location, which serve conservation, restoration, and comprehensive studies on our historical and cultural heritage. The main aim in such investigations is to obtain the maximum amount of information while keeping the damage as low as possible (Vandenabeele, 2004).

Vibrational techniques, especially Raman spectroscopyderived, mainly due to their non-destructive character, are well-established tools in the provenance and authenticity investigation of a wide range of archaeological artefacts and art historical objects, based on the characterization of their mineralogical and chemical composition and structure. Significant results have been obtained especially in the case of dyes, pigments and resins, providing additional arguments on archaeological and historical trade routes (Edwards, 2001).

A comprehensive study addressed to non-spectroscopists covering the basic aspects of Raman spectroscopy *Correspondence: D. Pop (danapop@bioge.ubbcluj.ro) techniques for such applications has been recently published (Smith and Clark, 2004).

Fourier-transform infrared (FT-IR) spectroscopy is considered to be one of the most appropriate experimental techniques for the analysis and the characterization of molecular compositions in the field of material science and cultural heritage. In particular, the minerals present in ceramics or in art objects, even in small amounts, are easily identifiable, so as to provide useful information on the raw materials' (clays, pigments etc.) provenance (Griffith, 1987; Shoval, 2003; Sodo et al., 2003).

Moreover, the modern Raman and infrared (IR) equipments may be equipped with fibre-optic probes that allow in situ examination of artefacts in museums or in archaeological sites.

However, there are disadvantages of the Raman and IR methods, which relate to the shortage of references and reliable databases, sensitivity to luminescence also in the NIR and to light absorption preventing the collection of optimum data for coloured, opaque samples etc.

Our study was carried out in order to test the efficiency of two of the potentially-relevant spectroscopic methods Raman and infrared (IR) spectroscopies, in addressing 
issues of interest to contemporary archaeology, in particular related to chert artefacts. The analytical techniques, i.e. FTRaman and (ATR-) FT-IR, have been selected considering the readily-available laboratory facilities, with the intention of testing the local analytical setup for chert investigations. The general aim is to propose and develop modern nondestructively and fast physical methods for interdisciplinary studies on Romanian archaeological valuable artefacts, which currently are poorly characterised from materials' point of view.

This contribution presents the first spectroscopic results on lithic artefacts in Romania.

\section{SAMPLES}

Here we report the spectroscopic analysis of seven "chert" flaked stone-tools recovered from Foeni (Fig. 1) archaeological site (Timiş County, Banat region, Romania). For the time being, Foeni represents one of the best-studied Neolithic sites from Banat. Excavations have been carried out since the 1990's (Draşovean, 1994; Haskel and Draşovean, 1994); these more than 15 years of archeological research performed by the team from the Banat Museum in Timişoara resulted in the richest collection of lithic materials in the area. However, detailed mineralogical information regarding lithic artefacts from Foeni is still missing.

Foeni village is located about $45 \mathrm{~km}$ southwest of Timişoara (the county's main city) between the Timiş River and Bega Channel. The archaeological excavations took place at two sites: Foeni - Cimitirul Ortodox (Orthodox Cemetery) representing the highest area within the village on its western side, and the more recently investigated Foeni - Gaz site, located $2 \mathrm{~km}$ northwest from the village, between Bega and Timiş River. The two sites have provided numerous lithic artefacts consisting of flaked or carved weapons and tools; additionally, bone tools and ceramic fragments were recovered.

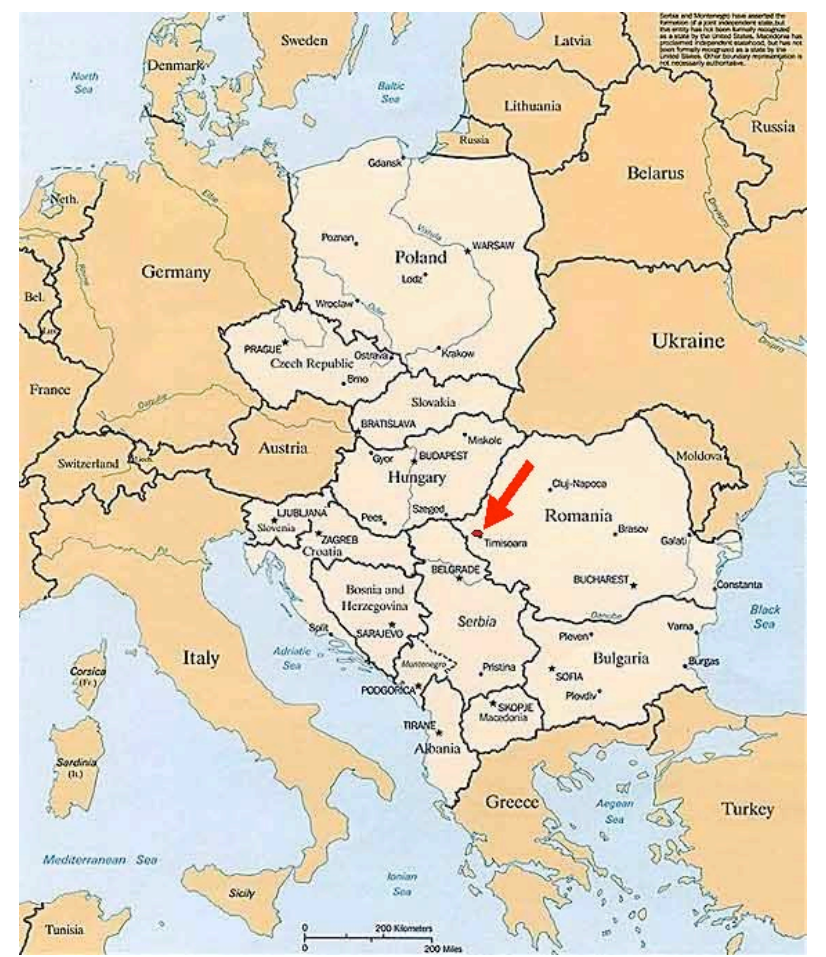

Fig. 1. Location of the Foeni archaeological site (Early Neolithic). Studia UBB, Geologia, 2008, 53 (1), 31 - 37
A recent publication (Spataro, 2006) focused on pottery and clay objects identified in several Early Neolithic sites in Banat, including Foeni. Based on ceramics typological features, Lazarovici (1979) attributed the Foeni sites to the second phase (II) of the Starčevo-Criş culture; radiocarbon dating on bone rests and artefacts points to the inhabitation of the sites during the first half of the $6^{\text {th }}$ millennium cal BC (Spataro, 2006).

The Foeni lithic findings under study were represented by flaked tools, i.e., "chert blades" used for various purposes (cutting, scraping etc.). An initial set of 95 artefacts provided by the archaeologists for compositional studies was subsequently classified into seven main categories based on colour, lustre and transparency (Table 1).

One sample from each category has been analyzed by micro-Raman and FT-IR spectroscopy. The photographs of the seven investigated chert artefacts are presented in Fig. 2.

Archaeologists designate as "chert" (or "flint" in the American literature) lithic materials characterized by relatively high hardness, semi-vitreous (translucent) to dull (opaque) diaphaneity, and splintery to conchoidal fracture. These physical properties pled for using this natural raw material mainly for producing cutting tools and weapons.

From a geological point of view, such materials may be defined as chert (usually lighter in colour) or flint (typically darker in colour); they are practically silica-rich rocks ("silicolites"), and in general they may be found as bands or nodules within successions of sedimentary rocks.

Their mineralogical composition is dominated by silica $\left(\mathrm{SiO}_{2}\right)$ species (polymorphs), of which granular, microcrystalline low temperature ("low", $\alpha$-quartz $\left(\mathrm{SiO}_{2}\right)$ ) is the most abundant. Other microcrystalline or poorly crystalline (chalcedony, moganite, opal-C, and opal-CT), and amorphous (opal-A) $\mathrm{SiO}_{2}$ phases may also be present. The mineralogical terminology used for the opal varieties considers their "crystallinity degree" based on X-ray diffraction patterns (Jones and Segnit, 1971). Thus, opal-A is used for diffractometrically amorphous $\mathrm{SiO}_{2}$, opal-CT for disordered $\alpha$-cristobalite with $\alpha$-tridymitic stacking, and opal-C for $\alpha$-cristobalite; based on additional electron microscopy (TEM) arguments, Elzea and Rice (1996) have stated that opals-CT and -C form a continuous series.

"Pure" silica minerals being colourless, the range of colours and transparency degrees of cherts depend on the type and amount of accessory minerals ("impurities") that accompany $\mathrm{SiO}_{2}$ varieties.

As a rule, there are a few non-silica mineral species (carbonates, micas, clay minerals, iron and manganese oxyhydroxides etc.) that may form intimate intergrowth with the $\mathrm{SiO}_{2}$ minerals.

The identification of the accessory minerals is essential in this case for material characterization, by providing clues for chert provenance studies based on specific discriminating geological factors.

Preparing thin sections from the samples for microscope investigation was not possible because of the special regime of these museum items; thus, the petrographical assignment of the samples could be based only on macroscopic observations. Accordingly, all the samples, except for F28 were defined as chert; F28 represents a silica-rich carbonate rock, or a carbonate-enriched chert. 

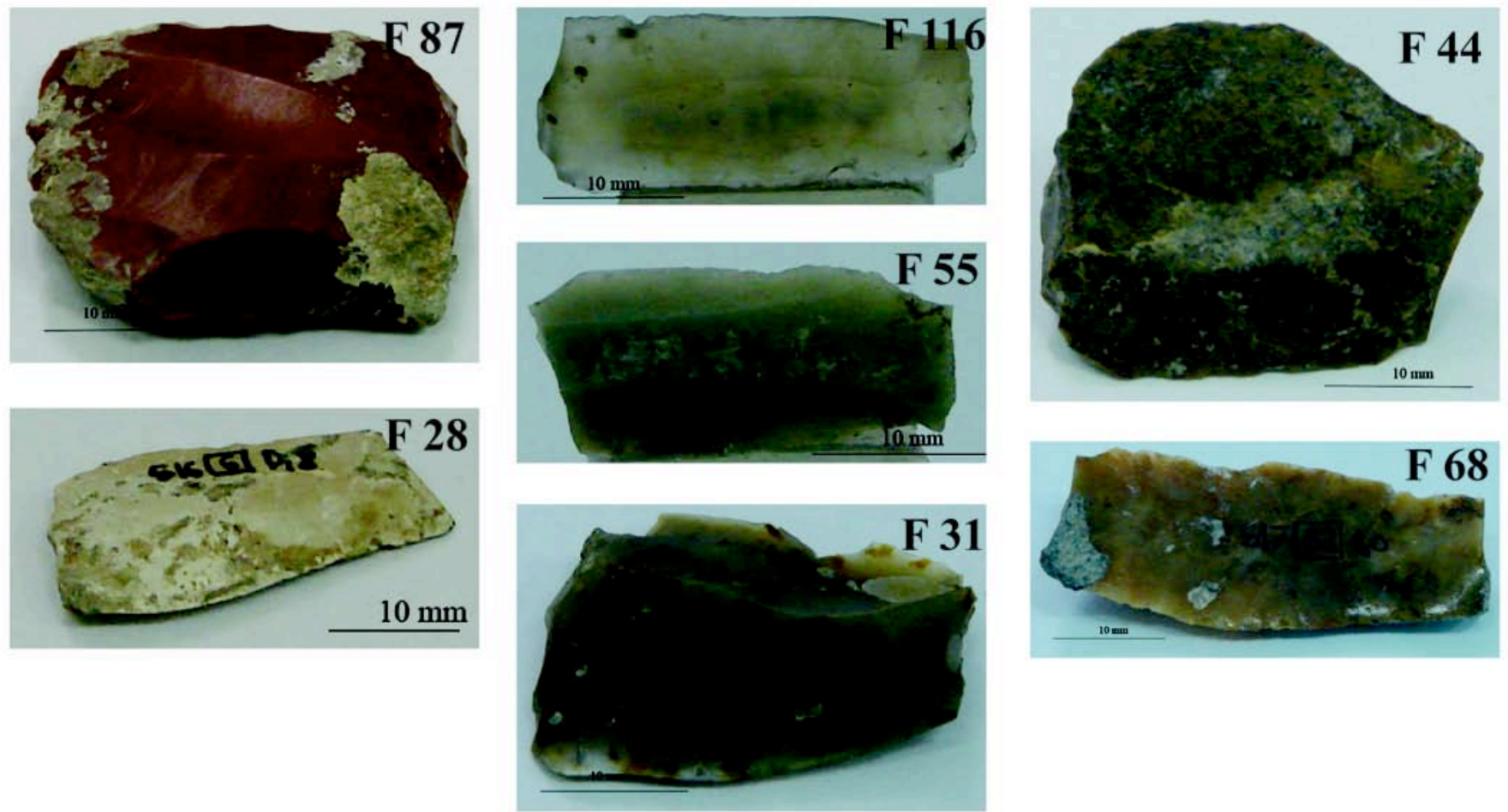

Fig. 2. Photographs of the chert artefacts under study. Scale bar: $10 \mathrm{~mm}$.

Table 1. Description of the investigated archaeological samples.

\begin{tabular}{|c|c|c|c|c|l|}
\hline No. & Inventory No. & $\begin{array}{c}\text { No. of artefacts } \\
\text { per category }\end{array}$ & $\begin{array}{c}\text { Archaeological context } \\
\mathbf{( S = t r e n c h / q u a d r a n t} \\
\text { /depth) }\end{array}$ & $\begin{array}{c}\text { Dimensions } \\
\text { (length/ width/ thickness) } \\
{[\mathbf{m m}]}\end{array}$ & Macroscopic description \\
\hline 1. & F68 & 22 & $\mathrm{~S} 17 / 32 / 1.00$ & $50 / 20 / 5$ & $\begin{array}{l}\text { Orange-yellow, slight greyish, broad } \\
\text { mottling, sub-translucent }\end{array}$ \\
\hline 2. & F116 & 10 & $\mathrm{~S} 17 / 11 /$ level I & $28 / 18 / 3$ & $\begin{array}{l}\text { Clear, yellowish/orangish, highly } \\
\text { translucent }\end{array}$ \\
\hline 3. & F87 & 27 & $\mathrm{~S} 16 / 1 / 1.00$ & $32 / 30 / 3$ & Red-orangish, dark greyish, opaque \\
\hline 4. & F31 & 3 & $\mathrm{~S} 16 / 23 / 1.00$ & $35 / 26 / 10$ & $\begin{array}{l}\text { Light grey-yellowish, spotted } \\
\text { (orange-yellow), translucent }\end{array}$ \\
\hline 5. & F55 & 14 & $\mathrm{~S} 16 / 16 / 0.6$ & $24 / 13 / 3$ & $\begin{array}{l}\text { Light green, slight greyish, sub- } \\
\text { translucent }\end{array}$ \\
\hline 6. & F44 & 16 & $\mathrm{~S} 16 / 15 / 0.6$ & $32 / 27 / 11$ & $\begin{array}{l}\text { Dark orange-reddish, dark greyish, } \\
\text { mottled (dark grey), opaque }\end{array}$ \\
\hline 7. & F28 & 3 & $\mathrm{~S} 16 / 6 / 0.8$ & $33 / 17 / 3$ & $\begin{array}{l}\text { White-yellowish, slightly greyish, } \\
\text { spotted (white, greyish), opaque }\end{array}$ \\
\hline
\end{tabular}

\section{EXPERIMENTAL}

Traditional mineralogical-petrographical studies on chert, based on routine physical-chemical methods (optical microscopy, X-ray powder diffraction, wet chemical analysis, microprobe etc.) involve, in principle, destructive preparation of the samples. By taking into account the type of samples under investigation, only non-destructive analytical methods had to be considered. FT-Raman and ATR-FT-IR analytical techniques have been selected considering the already available laboratory facilities ${ }^{1}$.

Our selection of methods was also based on the fact that IR methods had been already used for the characterisation of archeological cherts (Long et al., 2001), while Raman spectroscopy became one of the basic tools for interdisciplinary archeological investigations, in general (Edwards, 2001; Smith and Clark, 2004; Edwards and Chalmers, 2005).

\footnotetext{
${ }^{1}$ within the Molecular Spectroscopy, Chair of the Faculty of Physics,
} „Babeş-Bolyai” University, Cluj Napoca.
As time and technology have progressed, Raman spectroscopy has improved in such terms as spectral sensitivity, data collection speed, decreased sampling area, and decreased laser power required to produce usable, i.e., comparable and reproducible spectra.

One of the most important attributes of Raman spectroscopy is the fact that it requires very little power and no invasive sample preparation. These attributes are vital in the non-destructive study of museum objects or artefacts. As a powerful tool for the analysis of museum objects, microRaman technique using near infrared (NIR) excitation is preferred in order to avoid large fluorescence signal from coloured objects or artefacts.

\subsection{FT-Raman}

One major advantage of the FT-technique over the conventional dispersive Raman is the possibility to avoid the fluorescence of opaque samples, as in the present case, by using for excitation an infrared laser line instead of a visible one, which would be absorbed by the coloured samples. The 
low wave number spectral range (below $200 \mathrm{~cm}^{-1}$ ) is also available within a conventional FT-Raman acquisition at once, and this fact is particularly important for analysing crystalline materials, quartz in our case.

The Fourier-transform (FT)-Raman spectra were recorded using an Equinox 55 Bruker spectrometer with a FRA $106 \mathrm{~S}$ Raman module. A Nd:YAG laser operating at $1064 \mathrm{~nm}$ line was employed for the excitation. The power ranged from 30 to $370 \mathrm{~mW}$, depending on the Raman background behaviour. The spectral resolution was set to 4 $\mathrm{cm}^{-1}$ and 200 scans were accumulated for each spectrum. These conditions were adjusted following several signal adjustments in the OPUS software acquisition program. A Ge detector operating at the liquid nitrogen temperature was used for the detection of the signal.

\subsection{ATR-FT-IR}

In order to compare the suitability of the two main spectroscopic methods commonly used for archaeological investigations, infrared (IR) measurements were also performed on the selected samples.

An attenuated total reflectance (ATR) MIRacle module with ZnSe contact crystal was coupled to the Equinox 55 FT-IR Bruker spectrometer for recording the ATR-FT-IR absorbance spectra in the $4000-650 \mathrm{~cm}^{-1}$ range. The spectral resolution was $4 \mathrm{~cm}^{-1}$.

This setup was preferred over the conventional FT-IR using powdered samples (KBr-pellet technique) in order to keep the sample integrity and the non-destructive character of the museum objects' vibrational investigation.

However, we have to admit that the poor crystal contact with the rough surface of the samples and the consequently weak signal-to noise ratio in the ATR-FT-IR configuration hindered the recording of high quality FT-IR spectra.

\section{RESULTS AND DISCUSSION}

\subsection{FT-Raman results}

FT-Raman spectra collected from the analyzed samples are presented in Fig. 3.

The identification of the mineral phases was done by the fingerprint method, using reference spectra from databases (RRUFF Project database ${ }^{2}$ ) and values from the literature. The main vibrational modes (in $\mathrm{cm}^{-1}$ ) of $\alpha$-quartz (according to Etchepare et al., 1974) are located at: 1085, 464, 356, and $207 \mathrm{~cm}^{-1}$ (Raman active, $A_{1}$ symmetry); 1080, 778, 495, and 364 (Infrared active, $A_{2}$ symmetry); 1162, 1072, 795, 697, $450,394,265$, and $128 \mathrm{~cm}^{-1}$ (Raman and infrared active, $E$ symmetry).

According to Götze et al. (1998), the strongest band of moganite, assigned as the main symmetric stretchingbending mode, is located around the value of $504 \mathrm{~cm}^{-1}$.

The spectral results showed common bands for all the samples located at 129, 209, 359, 464, 795, 1162 (assigned to $\alpha$-quartz), and $504 \mathrm{~cm}^{-1}$ (assigned to moganite); besides, well-individualised particular bands were present in some spectra, located at $1085 \mathrm{~cm}^{-1}$ (sample F55) or $1095 \mathrm{~cm}^{-1}$ (sample F28). As expected for cherts, the artefacts under study, except for sample F28, revealed the presence of $\alpha$ -

${ }^{2}$ http://rruff.info/ quartz as major mineral phase, showing the most intense band located around $464 \mathrm{~cm}^{-1}$ (Fig. 3).

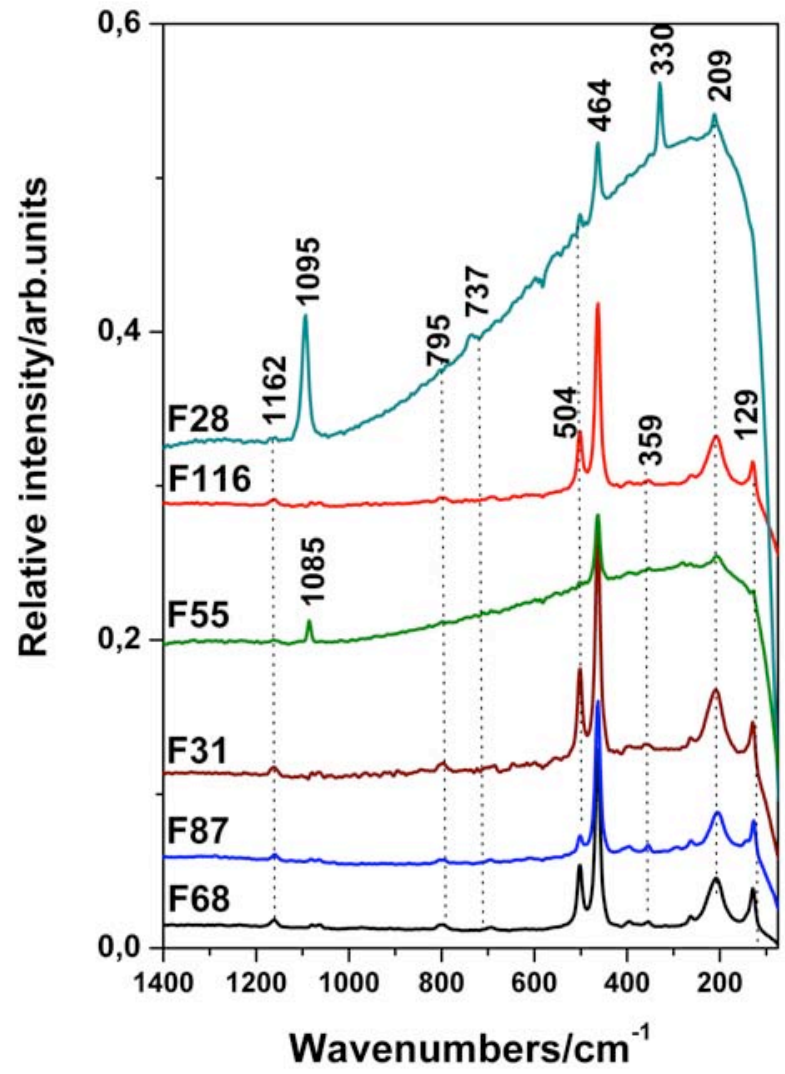

Fig. 3. FT-Raman spectra of several investigated chert artefacts (samples are denoted on the left side of the spectra according to their museum inventory number, also given in Table 1).

The assignment of the plotted bands is discussed in the text.

In the investigated spectra, the $504 \mathrm{~cm}^{-1}$ moganite band exhibits different relative intensities as compared to that of the main $\alpha$-quartz band at $464 \mathrm{~cm}^{-1}$; this feature is interpreted as an evidence for the presence of various amounts of moganite intergrown with the dominant $\alpha$-quartz (Götze et al., 1998) in all the studied samples, which is a common feature in natural microcrystalline silica samples (Kingma and Hemley, 1994; Pop et al., 2004).

Additionally, sample F55 contains calcite (band at 1085 $\mathrm{cm}^{-1}$ ). In sample F28 dolomite (main band around $1095 \mathrm{~cm}^{-1}$ and a second one around $\left.737 \mathrm{~cm}^{-1}\right)$ and a yet unidentified phase (band around $330 \mathrm{~cm}^{-1}$ ) were evidenced. Based on its relative strong band intensity, dolomite seems to represent a significant mineral component of this sample, a fact that may explain its lack of transparency. However, we have not performed quantitative Raman evaluations, thus the estimation of the relative participation of the non-silica minerals is only tentative.

\subsection{ATR-FT-IR results}

Our ATR-FT-IR measurements were performed on several representative raw (bulk, not-powdered) samples. Selected spectra of the most suitable samples for IR measurements show rather different spectral baselines, strongly related to the quality of the crystal (as a component of the analytical ATR setup) contact with the sample. Variable spectral contrast is thus a consequence of surface roughness at the grain scale. Typical ATR-FT-IR spectra of three samples, including the mineralogically most complex 
ones (F28 and F55) is presented in Fig. 4. The spectral acquisitions for the other four samples revealed poor signalto-noise ratio, therefore they were omitted from the figure.

In order to identify the molecular species, the vibrational data were compared with reference databases (Sadtler Database "Minerals and Clays" library ${ }^{3}$, California Institute of Technology ${ }^{4}$, and RRUFF Project database ${ }^{5}$ ), as well as with published IR data, e.g. Long et al. (2001) for ground chert samples. According to the references, the main $\alpha$-quartz IR active bands are located around 368, 393, 460, $509,692,778,797,1080$, and $1168 \mathrm{~cm}^{-1}$.

All the samples under study showed the presence of $\alpha$ quartz bands at $694,776,796,1080$, and $1167 \mathrm{~cm}^{-1}$, with little shifts of the wave numbers and variable relative intensities among the three spectra, in good agreement with the Raman results.

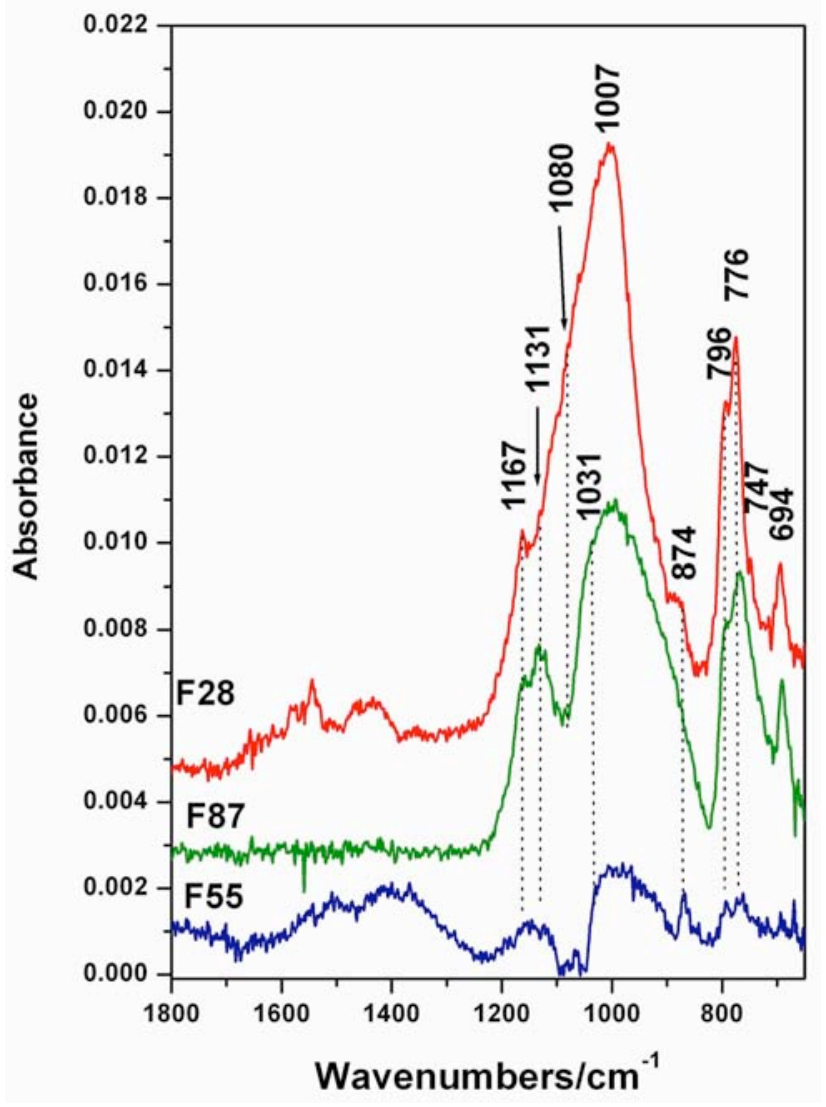

Fig. 4. Typical ATR-FT-IR spectra of the investigated artefacts (samples are denoted on the left side of the spectra according to their museum inventory number, also given in Table 1). The assignment of the plotted bands is discussed in the text.

Sample F55 (Fig. 4) shows IR spectral features characteristic for calcite, a mineral identified in the corresponding Raman spectrum. The IR reflectance spectrum collected from a calcite single crystal (Williams, 1995) revealed prominent bands at 1574, 1413 (asymmetric stretching), 874 (out of plane bending) $\mathrm{cm}^{-1}$ and a weak band at $710 \mathrm{~cm}^{-1}$ (in plane bending mode). In our measured spectrum, most of these bands were recorded $(710,874$, and $1419 \mathrm{~cm}^{-1}$ ), showing weak to medium relative intensities. Thus, the IR pattern re-confirms the presence of calcite as accessory mineral in sample F55.

\footnotetext{
${ }^{3}$ http://www.bio-rad.com/ir.html

${ }^{4}$ http://minerals.gps.caltech.edu/

${ }^{5}$ http://rruff.info/
}

As indicated by the relative intensities of the Raman bands (Fig. 3), sample F28 contains significant amounts of dolomite. According to the references (RRUFF database), dolomite exhibits the IR absorbance main bands at 728,877 , 1156 , and $1427 \mathrm{~cm}^{-1}$. The presence of dolomite in our IR spectrum (Fig. 4) is confirmed, the band at $728 \mathrm{~cm}^{-1}$ (also indicated by Long et al. (2001) as belonging to dolomite) could be the one shifted around $747 \mathrm{~cm}^{-1}$, while the mode centred at $1441 \mathrm{~cm}^{-1}$ is present as a broaden medium band.

The most prominent feature in the IR spectrum of sample F28 is an intense broad band centred at $1007 \mathrm{~cm}^{-1}$ (Fig. 4) with additional shoulders at 1031 and $1131 \mathrm{~cm}^{-1}$. This complex band is also present in the spectrum of sample F87. We suppose that this contribution is due to illite, based on its reference IR spectrum (California Institute of Technology). The illite reference spectrum exhibits additional bands, most of them overlapping $\alpha$-quartz, thus being more difficult to assign in our case: 690, 778, 1000, $1066,1596 \mathrm{~cm}^{-1}$. The RRUFF database includes only one common clay mineral species, i.e. montmorillonite, whose main IR band is located around $945 \mathrm{~cm}^{-1}$. Thus, contributions from other clay minerals in the spectral features of samples F28 and F87 cannot be excluded.

The mineral assemblage consisting of dolomite, illite and $\alpha$-quartz evidenced by Raman and IR spectroscopy for sample F28 may point to a (possibly hydrothermally-) altered rock as its geological source.

\subsection{Discussion}

FT-IR has been previously tested for chert analysis, especially in the case of apparently homogeneous sets of raw materials. It was already found that the irregular reflectance characteristics of the rough surface of the samples led to unsatisfactory results. Concerning our investigation using the ATR-IR technique for representative archaeological artefacts from Foeni, curved and irregular sample surfaces proved to be not very suitable for analysis, due to the poor crystal contact. Thus in such cases, when it is not possible to cut and polish the specimens, Raman spectroscopy may still provide much better analytical results as compared to IR.

However, a small amount $(0.1 \mathrm{~g})$ of ground material removed from the artefacts was enough for preparing $\mathrm{KBr}$ pellets for IR measurements and allowed the chert samples to be grouped into source categories based on accessory minerals (Long et al., 2001). Our main goal being the nondestructive investigation of the artefacts, we did not perform measurements using the $\mathrm{KBr}$-pellets technique, which is still preferable for more accurate IR analysis.

In the same time, the presence of hydrous species, in our case illite, is better evidenced in IR as compared to Raman spectra; this is due to the excellent ability of IR to detect even traces of hydrous minerals. This is an argument for using combined Raman and IR techniques for the study of cherts.

To the best of our knowledge, the present study provides the first attempt of non-destructive investigation of archaeological artefacts in Romania, by using optical spectroscopic methods (FT-Raman and FT-IR), fact that is of special importance for the poorly- studied local museum collections. Systematic further studies could be designed to solve explicitly stated archaeological questions. These data would add to the previous investigations already performed 
in the region and would fill "blank spots" on possible sources of chert raw materials in Central-South-East Europe, in the framework of the Starčevo-Criş culture and the Neolithisation of the Central Balkans (Spataro, 2006).

\section{CONCLUSIONS}

The chert specimens from Foeni Neolithic site (Banat region, Romania) selected for the spectroscopic investigation showed different macroscopic characteristics (colour, texture, and transparency) and they were representative for larger groups of chert artefacts recovered from the archaeological site.

Fourier-transform vibrational spectroscopy has nondestructively been applied for the mineralogical investigation of the artefacts, semi-quantitative estimations being possible. Except for one sample (F28), the dominant mineral phase was concluded to be $\alpha$-quartz, vibrational data exhibiting the characteristic bands of the microcrystalline $\mathrm{SiO}_{2}$. This result has been expected, taking into account the nature of the lithic artefacts (cherts). A less common result was the analytical confirmation of the presence of non-silica minerals (calcite, dolomite, and clay minerals), which were sample-specific.

From petrographic point of view, most of the samples could be defined as chert. In the case on sample F28, the presence of specific accessory minerals (dolomite, illite) pointed to distinctive genetic conditions. The corresponding raw material might have resulted from the silicification of a carbonatic (dolomitic) rock; it was defined as silica-rich dolomite, or dolomitic chert.

In spite of their different appearances at macroscopic level, based on single point FT-Raman measurements the chert artefacts under study could not be assigned to distinctive groups of raw materials, in order to provide specific arguments for provenance studies. In such cases sets of measurements (mapping) are required for statistically characterizing each specimen.

As compared to FT-Raman, the ATR-FT-IR spectra were less suitable for raw material discrimination in the case of chert artefacts in the non-destructive measurement setting. However, in the $650-1800 \mathrm{~cm}^{-1}$ range several specific bands of non-silica minerals could be evidenced, illite being identified only in the IR pattern of sample F28. Thus, IR spectral features may serve as indices for the geological sources, when correlated with the more accurate FT-Raman data.

This study on chert artefacts from Romania based on non-destructive optical spectroscopic methods showed that there are premises for a systematic investigation of highly valuable museum collections, in particular, in terms of chert geology. The pre-requisite conditions for consistent results would be a micro-Raman scanning of the objects' area, or Raman imaging instead of single spectrum analyses per sample, a larger number of investigated artefacts, similar/comparable analytical procedures based on reliable Raman databases, and similar investigations on presumable source rock samples from known, proximally-located geological areas of interest.

As complementary methods of investigation for cherts, possibly providing additional and more specific clues for provenance studies, studies on mineral inclusions, of trace elements, or of the isotope signature are strongly advisable.
Acknowledgments. We would like to thank Prof. Dr. Florin Draşovean (Banat Museum in Timişoara) for providing the archaeological samples. Mr. Otis Norman Crandell, from "1 Decembrie 1918" University of Alba Iulia, Department of Archaeology and History, is acknowledged for corrections to the English version and useful discussions and suggestions. The authors address special thanks to Prof. Lutz Nasdala and to other two reviewers for their useful comments and suggestions that substantially contributed to the improvement of the manuscript.

\section{R E F E R E NC E S}

Draşovean, F. 1994, The Petreşti Culture in Banat. Analele Banatului, serie nouă, Arheologie-Istorie, III: 139-170.

Edwards, H.G.M. 2001, Raman spectroscopic analysis of art and artefacts of relevance to the preservation of cultural heritage. In Handbook of Raman Spectroscopy: From the Research Laboratory to the Process Line (Lewis, I.R., Edwards, H.G.M., Eds.), Marcel Dekker Inc., New York, p. 1011-1044.

Edwards, H.G.M., Chalmers, J.M. (Eds.) 2005, Raman Spectroscopy in Archaeology and Art History. Royal Society of Chemistry, Cambridge, $508 \mathrm{p}$.

Elzea, J.M., Rice, S.B. 1996, TEM and X-ray diffraction evidence for cristobalite and tridymite stacking sequences in opal. Clays and Clay Minerals, 44: 492-500.

Etchepare, J., Merian, M. \& Smetankine, L. 1974, Vibrational normal modes of $\mathrm{SiO}_{2}$. I. $\alpha$ and $\beta$ quartz. The Journal of Chemical Physics, 60: 1873-1876.

Götze, J., Nasdala, L., Kleeberg, R. \& Wenzel, M. 1998, Occurrence and distribution of „moganite" in agate/chalcedony: a combined micro-Raman, and cathodoluminescence study. Contributions to Mineralogy and Petrology, 133: 96-105.

Griffith, W.P. 1987, Advances in the Raman and Infrared Spectroscopy of Minerals. In Spectroscopy of Inorganic Based Materials (Clark, R.J.H. \& Hester, R.E., Eds.), J. Wiley and Sons Ltd., New York, p. 119-186.

Jones, J.B., Segnit, E.R. 1971, The nature of opal. Part 1: Nomenclature and constituent phases. Journal of the Geological Society of Australia, 8: 57-68.

Analele Banatului, serie nouă, Arheologie-Istorie, III: 4585.

Kingma, K.J., Hemley, R. 1994, Raman spectroscopy study of microcrystalline silica. American Mineralogist, 79: 269-273.

Lazarovici, G. 1979, Neoliticul Banatului. Bibliotheca Mvsei Napocensis, 4: 94-101.

Long, D.G.F., Silveira, B., \& Julig, P. 2001, Chert analysis by infrared spectroscopy. In A Collection of papers presented at the $33^{\text {rd }}$ annual meeting of the Canadian Archaeological Association (Pilon, J.-L., Kirby, M.W., \& Thériault C., Eds.), The Ontario Archaeological Society Inc., Toronto, p. 256-267.

Pop D., Constantina C., Tătar D. \& Kiefer W. 2004, Raman spectroscopy on gem-quality microcrystalline and amorphous silica varieties from Romania. Studia Universitatis Babes-Bolyai, Geologia, 49 (1): 41-52.

Shoval, S. 2003, Using FT-IR spectroscopy for study of calcareous ancient ceramics. Optical Materials, 24 (1-2): 117-122. 
Smith G.D., Clark R.J. 2004, Raman microscopy in archaeological science. Journal of Archaeological Science, 31 (8): 1137-1160.

Sodo, A., Nardone, M., Ajò, D., Pozza, G. \& Bicchieri, M. 2003, Optical and structural properties of gemmological materials used in works of art and handicraft. Journal of Cultural Heritage, 4 (Suppl. 1): 317-320.

Spataro, M. 2006, Pottery typology versus technological choices: an early Neolithic case study from Banat
(Romania). Analele Banatului, serie nouă, Arheologie Istorie, XIV (1): 63-78.

Vandenabeele, P. 2004, Raman spectroscopy in art and archaeology. Journal of Raman Spectroscopy, 35: 607-609.

Williams, Q. 1995, Infrared, Raman and Optical Spectroscopy of Earth Materials. In Mineral Physics and Crystallography, A Handbook of Physical Constants (Ahrens, T.J., Ed.), American Geophysical Union, Washington D.C., p. 291-302. 